IZA DP No. 8425

Convergences in Men's and Women's Life Patterns:

Lifetime Work, Lifetime Earnings, and Human Capital Investment

Joyce Jacobsen

Melanie Khamis

Mutlu Yuksel

August 2014 


\title{
Convergences in Men's and Women's Life Patterns: Lifetime Work, Lifetime Earnings, and Human Capital Investment
}

\author{
Joyce Jacobsen \\ Wesleyan University \\ Melanie Khamis \\ Wesleyan University \\ and IZA \\ Mutlu Yuksel \\ Dalhousie University \\ and IZA
}

Discussion Paper No. 8425

August 2014

IZA

P.O. Box 7240

53072 Bonn

Germany

Phone: +49-228-3894-0

Fax: +49-228-3894-180

E-mail: iza@iza.org

\begin{abstract}
Any opinions expressed here are those of the author(s) and not those of IZA. Research published in this series may include views on policy, but the institute itself takes no institutional policy positions. The IZA research network is committed to the IZA Guiding Principles of Research Integrity.

The Institute for the Study of Labor (IZA) in Bonn is a local and virtual international research center and a place of communication between science, politics and business. IZA is an independent nonprofit organization supported by Deutsche Post Foundation. The center is associated with the University of Bonn and offers a stimulating research environment through its international network, workshops and conferences, data service, project support, research visits and doctoral program. IZA engages in (i) original and internationally competitive research in all fields of labor economics, (ii) development of policy concepts, and (iii) dissemination of research results and concepts to the interested public.
\end{abstract}

IZA Discussion Papers often represent preliminary work and are circulated to encourage discussion. Citation of such a paper should account for its provisional character. A revised version may be available directly from the author. 


\section{ABSTRACT \\ Convergences in Men's and Women's Life Patterns: Lifetime Work, Lifetime Earnings, and Human Capital Investment ${ }^{*}$}

The changes in women and men's work lives have been considerable in recent decades. Yet much of the recent research on gender differences in employment and earnings has been of a more snapshot nature rather than taking a longer comparative look at evolving patterns. In this paper, we use 50 years (1964-2013) of US Census Annual Demographic Files (March Current Population Survey) to track the changing returns to human capital (measured as both educational attainment and potential work experience), estimating comparable earnings equations by gender at each point in time. We consider the effects of sample selection over time for both women and men and show the rising effect of selection for women in recent years. Returns to education diverge for women and men over this period in the selectionadjusted results but converge in the OLS results, while returns to potential experience converge in both sets of results. We also create annual calculations of synthetic lifetime labor force participation, hours, and earnings that indicate convergence by gender in worklife patterns, but less convergence in recent years in lifetime earnings. Thus, while some convergence has indeed occurred, the underlying mechanisms causing convergence differ for women and men, reflecting continued fundamental differences in women's and men's life experiences.

JEL Classification: J3, J16, J24, N3

Keywords: gender earnings gap, lifetime work, lifetime earnings, human capital investment

Corresponding author:

Joyce Jacobsen

Department of Economics

Public Affairs Center 332

238 Church Street

Middletown, CT 06459-0007

USA

E-mail: jjacobsen@wesleyan.edu

\footnotetext{
${ }^{*}$ The authors would like to thank the participants of the IZA Workshop on Gender Convergence in April 2014 and the seminar participants at Middlebury College, Wesleyan University and the IAFFE Annual Conference for helpful comments. The authors also would like to thank the editors Sol Polachek and Kostas Tatsiramos and two anonymous referees for their helpful suggestions on this paper.
} 


\section{Introduction}

The changes in women's and men's work lives since the mid-twentieth century have been considerable. The best known of such changes include women's rising labor force participation, with some leveling off in more recent years; the narrowing of the gender wage gap, again with periods of leveling; and men's falling labor force participation, exacerbated in part by the most recent economic downturn. These changes are true for most societies, although our specific statements in this paper will refer for the most part to the US experience.

These changes have also made it harder for researchers to generalize about the experience of the typical woman or man. Workforce experiences, measured in terms of labor force attachment, hours worked, and returns per hour, have increasingly diverged for those with higher levels of human capital and lower levels of human capital. In addition, the current focus of much labor economics research on economic inequality within gender and within the labor force as a whole has reinforced this movement away from generalization regarding economywide patterns.

In addition, much of the most recent research on gender differences in employment and earnings has been of a more snapshot nature rather than taking a longer comparative look at evolving patterns. In contrast, in this paper we use 50 years (1964-2013) of US Census Annual Demographic Files (March Current Population Survey) to track the changing levels of and returns to human capital (both education and potential work experience) by gender through estimation of comparable earnings equations at each point in time. We are also able to track changes in self-selection into the labor market for both women and men and the effects of selection on earnings. While our paper confirms many of the trends that papers examining subsets of the data also find, it also attempts to refocus on the general trends by gender rather than on divergence within gender. This has the effect in part of refocusing attention on the fact that women's and men's labor market experiences, while more similar now than in the past, are also still quite different in terms of both year-to-year and total lifetime outcomes.

This time-series comparative methodology also allows us to see the very clear effects of both the longer upward trend in US workforce participation and returns to participation for women 
(and the slight downward trend for men in participation) along with the recent changes in the labor market driven by the long recession. These effects include a narrowing of the gender differentials in expected lifetime labor force attachment, lifetime hours worked, and lifetime earnings. These lifetime calculations provide another way of considering the full effect on women and men of the labor market changes over their work lifetime rather than focusing on yearly variations in earnings and participation. Furthermore, lifetime calculations, in particular with respect to labor force participation, are important when analyzing human capital investments (Polachek 1975b).

The paper is structured as follows: Section II contains discussion of previous related work. This is followed by a discussion of how we set up our analytical structure to be consistent across this fifty-year time span (Section III). Section IV provides our graphical results and discussion of those results. Section $\mathrm{V}$ concludes and indicates directions for follow-up work. 


\section{Literature Review}

Recent research on male and female labor force participation, hours worked and returns to human capital investment finds some clear trends over time (Goldin 2014). Labor force participation rates of men and women have converged over time and there has been narrowing of the gender earnings gap. This convergence of labor force participation, earnings and the educational attainment of men and women over time can probably be explained by a combination of structural changes in the economy, technology advances in workplace, declines in fertility, in home production, child care provision and policies addressing discrimination, divorce, marriage and labor markets (Fernández 2013). Fernández (2013) argues that social transformation and a revolution in social attitudes towards married women in the labor market can also explain increases in the labor force participation of women.

However, in explaining the gender gap in earnings social changes in and of themselves may not be sufficient. Investment in human capital and time allocation towards the labor market, thus increasing the total work experience of women, are important determinants to understand female earnings (Mincer and Polachek 1974). Without this human capital investment, social change would likely not have led to substantial measured effects on gender differences. Looking at the evolution of the gender earnings gap and human capital investments over the time period 1970 to 2010, Goldin (2014) indeed finds that underlying differences in human capital between men and women have decreased and the portion of the gender earnings gap attributed due to these differences has been reduced.

These trends of convergence in hourly earnings for men and women have been documented and explained for particular recent time periods. For example, O’Neill and Polachek (1993) document earnings from 1890 to 1990 and find that since 1976 the gender earnings gap declined until 1990 by about 1 percent a year. They attribute much of this convergence in acquired characteristics such as education and work experience, while additional factors accounting for part of the narrowing include the returns to experience for women and declines in hourly earnings in blue-collar work, which is clearly a more male-dominated sector. 
However, for the 1990s, Blau and Kahn (2006) find that a slowing convergence in the gender pay gap cannot be explained by changes in human capital as continued improvements for women occurred through the 1980s and 1990s. Underlying mechanisms that might explain the slowdown could be changes in the selection into the labor force and changes in unobservable gender characteristics (Blau and Kahn 2006). Blau and Kahn (2005) found over the time period of the 1980s a rapid growth of female labor supply. Polachek (2006) shows that the slowing convergence can be explained by changes in women's relative to men's labor force participation in the latter 1990s. For the period 1979 to 2001 O'Neill (2003) finds a narrowing of the returns to potential experience for men and women, which is consistent with the earlier studies (Blau and Kahn 2006; O’Neill and Polachek 1993).

Overall, a convergence of earnings for men and women has been documented for the period from the 70s to the early late 90s (Blau and Kahn 2000). Polachek and Robst (2001) find for the 1970s a rapid increase in female labor force participation that is not observed in the 1980s. However, in the 1980s they find that the earnings gap narrowed more quickly than 1970s, which they explain by the higher labor force entry rate of women with relatively less human capital in the 1970s. At the same time rising inequality and increases in the returns to skill might account for a potential opposing trend of widening the gap in turn. Autor, Katz and Kearney (2008) analyze U.S. wage inequality over the 1980s and 1990s and attribute this to skill-biased technological change. The effect on the gender earnings gap is not entirely clear: one hand Blau and Kahn (2000) argue that the trend in wage inequality is similar for men and women over this period and on the other hand Bacolod and Blum (2010) find that a narrowing gender gap and increases in wage inequality are consistent with differential returns to skills, which favor women.

In explaining potential candidates for the residual gender wage gap, while observable attributes such as educational attainment cannot account for this, Goldin (2014) argues that increases in the earnings gap by age, and the increases in the earnings gaps and hours worked within and across occupations and sectors can explain large parts of the remaining earnings gap. Occupational characteristics as an explanation of the gender wage gap were already found to 
be an important determinant for the period up to 2001 (O' Neill 2003). This widening gender gap within occupations over the lifecycle is also consistent with the problem of life-cycle division of labor within the family where husband and wife have differential human capital investments that in turn have effects on female wage gap. The male-female earnings gap for singles does not appear to widen the same way (Polachek 1975a).

To understand gender convergence patterns over time, a number of factors, including the selection into the labor force, earnings, composition effects of the labor force, returns to education and experience, and hours worked need to be analyzed in further detail. The paper most closely related to our current research is by Mulligan and Rubinstein (2008), who investigate selection into the labor force and hourly earnings for women over time. In particular, they find that over time women's selection into labor force participation changed from negative selection in the 1970 s to positive selection in the 1990 s. $^{1}$ Our finding and Mulligan and Rubinstein's finding are consistent with the human capital approach: women with less human capital may drop out of the labor force and women with more human capital may have entered in greater numbers, which in turn implies increased selectivity due to human capital and not necessarily due to ability. This indicates that the selection rule was changing over time for women and a different composition of women was selecting into the labor force. This can explain the narrowing of the gender wage gap at the same time that there are increases in within-gender wage gaps.

We also account for self-selection into the labor force for men and women over the entire period. Thus we extend earlier basic research into the patterns of both returns to human capital investment and levels of human capital investment over this fifty-year time period to see whether our results, which utilize a consistent estimation methodology over the full time period, are both consistent with other researchers' results and internally consistent in terms of tracking both investments in human capital and returns to human capital from year to year.

\footnotetext{
${ }^{1}$ Negative selection into the labor force means that the unobservables driving selection into work participation are negatively correlated with factors leading to higher earnings; positive selection means there is a positive correlation. Thus the apparently relatively less productive women were more likely to work in the earlier time period, while the apparently relatively more productive women were more likely to work in the later time period.
} 
Building on the previous research in the area, we are able to extend the analysis over a longer timespan than most other studies, considering returns to education and potential experience as well as calculating additional descriptive measures of synthetic lifetime labor force attachment, lifetime earnings and lifetime hours worked. Our synthetic worklife estimates are similar in spirit to those calculated by the Census Bureau (U.S. Dept. of Commerce 2011). Closely related work by Polachek (1975a) and Goldin and Polachek (1987) also use work probabilities at each age in a given US census year in their work to understand earnings differentials; Joshi and Davies (2002) take a related approach to study women's lifetime earnings using British data. 


\section{Data and Regression Specification}

For this paper we employ 50 years (1964-2013) of the US Census Annual Demographic Files (March Current Population Survey). We run two regressions per year (one for males and one for females). This amounts to 100 regressions over the 50 -year timespan. The data for our paper were downloaded from the Integrated Public Use Microdata Series (IPUMS) CPS webpage at the University of Minnesota (http://cps.imps.org/cps/).

We restrict our sample to individuals aged 25 to 65 and obtain individual characteristics such as gender, age, race, marital status, years of education, educational attainment, urban-rural location and regions. These variables are all measured as consistently as possible over the full sample period, although changes in CPS sampling procedure and definitions can show up as jumps in the data.

All regressions are run separately by gender. From the data we create dummy variables for race that cover whites, black and other races. ${ }^{2}$ The marital status is a dummy variable that takes the value 1 for married with spouse present or absent and 0 for any other status.

To account for geographic effects of rural-urban location we include a dummy that takes the value 1 for location in the central city or outside the central city and 0 for not in the metropolitan area. For location within the United States we use the regional codes from the CPS for the Northeast, Midwest, South and West region.

For educational attainment we create three categories: high school attendance without high school diploma, high school diploma or equivalent and some college attendance but no degree, and bachelor degree and above. ${ }^{3}$

For years of education we code 0 to 22 years of education from the CPS, which we employ to obtain potential experience. Potential experience for males and females is calculated by subtracting years of education minus 6 from individual age. In our OLS regressions and the two-

\footnotetext{
${ }^{2}$ The Hispanic category is only available after 1971. For a consistent definition, the Hispanic/Latino population is classified as 'other races'.

${ }^{3}$ We coded the category 'high school diploma' from the CPS data category of 'High School Diploma or equivalent'. The GED is therefore counted as high school diploma or equivalent.
} 
step selection-corrected Heckman model we include potential experience as a quartic function. $^{45}$

For our main left-hand side variables in the hourly earnings regressions, for our calculation of the wage we use the log hourly earnings in real terms and log annual earnings in real terms. To obtain this we use the wage and salary income variable from the CPS that records individuals' total pre-tax wage and salary income from the previous calendar year (thus the latest year for the earnings data are 2012, and the earliest 1963, but we will refer to earnings by the year of the sampling). We then convert this wage and salary income variable to real terms, with the base year 2013. We obtain log annual earnings taking the logarithm from this. For the hourly numbers we divide the annual wage and salary income variable by the annual hours worked before converting it into the logarithm of hourly earnings. ${ }^{6}$

Annual hours worked are calculated from weeks worked last year multiplied by usual hours worked per week in the last year after 1976. Before 1976 annual hours worked are calculated from hours worked last week multiplied by weeks worked in the last year, available in intervals. This particular change causes a one-time jump in the data series at $1976 .^{7}$

To analyze convergence and divergence of earnings over time, we estimate separate hourly earnings regressions for each year $t$ and for each gender $j$ :

(1) $w_{i j t}=\alpha_{j t}+\beta_{j t} X_{i j t}+\varepsilon_{i j t} \quad$ for $\mathrm{t}=1964,1965, \ldots$ 2013, and $\mathrm{j}=1$ and 2 .

Thus we estimate the hourly earnings equation (1) as a yearly cross-sectional regression with individual data, where data are available for a sample of individuals $i$ of gender $j$ (men or women) in year $t$. This yields, for our sample, 100 different equations (50 years times two

\footnotetext{
${ }^{4}$ See Mincer (1974) for the original specification for the inclusion of experience as a quartic function and the review article on the Mincer equation by Lemieux (2006).

${ }^{5}$ Potential experience can lead to biases as women have roughly the same potential experience but less actual experience than men. Over time the actual experience of women is rising relative to men's actual experience while potential experience remains probably relatively constant.

${ }^{6}$ We code the observations that have less than 1 and greater than 1000 US\$ hourly earnings as missing. Annual earnings greater than 9999997 US\$ we also code as missing.

${ }^{7}$ We choose to let this variable definition change cause a one-time level reset in the data rather than include a dummy in the hourly earnings equation for this so as to keep the regression specification identical across the years.
} 
genders). $X$ is a vector that includes educational attainment dummies, potential work experience as a quartic, race dummies, a rural-urban dummy and regional dummies. The base categories for our regressions are high school dropout, race other than white or black, rural and the West region.

We estimate (1) as an OLS regression, without selection-correction and then also estimate a two-step Heckman selection model (Heckman 1979). We mainly discuss the Heckman results in the following sections, but ran OLS for comparison and show those results in the appendix.

In the first stage we estimate the participation equation (2) that includes an exclusion restriction. As a determinant for selection into labor force participation, the vector $\mathrm{Z}$ includes marital status in addition to the variables included in X. Contrary to Mulligan and Rubinstein (2008), who assume no selection bias on the part of men, we include the marital status, hence being married, into the selection equation for both men and women. Mulligan and Rubinstein (2008) also interact the marital status with the number of children aged 0-6. However, the number of own children under age 5 in the household is only available from 1968 onwards, thereby this would limit our sample by a few years.

For this reason we only use marital status in our selection equation as an exclusion restriction in the results we present here. ${ }^{8}$ However, we have also estimated the Heckman selection models with marital status interacted with the number of children and found similar results over the period (1968 onwards) where both variables are available. ${ }^{9}$

(2) $P_{i j t}(L F P=1 \mid Z=1)=\Phi(Z \delta)$

From (2) we compute the inverse Mills ratio $\widehat{\lambda_{l \jmath t}}=\lambda\left(Z_{i j t} \hat{\delta}_{j t}\right)$.

\footnotetext{
${ }^{8}$ Heckman (1980) in his original paper includes linear and squared terms for children less than six, 1967 assets, husband's age, husband's education, husband's hourly earnings, wife's education and interactions of all linear terms (page 226 Table 5.1). He uses the cross-section data of the 1967 National Longitudinal Survey of Work Experience of Women Age 30-44 and has other variables available that the CPS does not include for our project over a 50 year horizon.

${ }^{9}$ Full regression results, including all coefficients, as well as results from these alternative specifications, are available upon request from the authors.
} 
Then we estimate the 100 hourly earnings regressions with the selection correction term included:

(3) $w_{i j t}=\alpha_{j t}+\beta_{j t} X_{i j t}+\rho_{j t} \widehat{\lambda_{l j t}}+\varepsilon_{i j t}$

The inverse Mills ratio obtained from a probit regression then corrects our hourly earnings regressions for the selection into labor force participation. It measures the degree of selection bias of persons in our sample.

In addition to degree of selection over time and earnings over time based on the Heckman regression models, we calculate the synthetic worklife measures of years in the labor force, total hours worked, and total earnings based on average outcomes by age group by gender in a given year. We calculate this for a person just entering the age range on which we are focusing, namely someone age 25 in the given year, and consider what their worklife experience would be if they experience the same average experience in the future as those persons now older than them in the workforce are experiencing in the given year. This could be viewed as a steady state calculation wherein a static economic system would yield the same outcomes for each person on average indefinitely into the future. Thus we calculate the 100 expectations:

(4) $E(L T Y)_{j t}=\sum_{i=25}^{65} p_{i j t}$

where $E(L T Y)_{j t}$ is the expected lifetime years in work for a person aged 25 of gender $j$ in year $t, i$ is an age group of gender $j$ in year $t$ and $p_{i j t}$ is the probability of employment for age group $i$ of gender $j$ in year $t$, which is the same as the proportion of the gender-age group that is employed in the given year $t$.

In addition to (4), we can calculate the expected lifetime hours worked as in (5) below, and the expected lifetime earnings as in (6) below:

(5) $\mathrm{E}(\mathrm{LTHW})_{j t}=\sum_{i=25}^{65} p_{i j t} \bar{h}_{i j t} \bar{W}_{i j t}$

where $\mathrm{E}(\mathrm{LTHW})_{j t}$ is the expected lifetime hours worked for a person aged 25 of gender $j$ in year $t, \bar{h}_{i j t}$ is the average hours worked per week for employed individuals in age group $i$ of gender $j$ 
in year $t$, and $\bar{w}_{i j t}$ the number of weeks worked for employed individuals in age group $i$ of gender $j$ in year $t$.

(6) $\mathrm{E}(\mathrm{LTE})_{j t}=\sum_{i=25}^{65} p_{i j t} \bar{e}_{i j t}$

where $\mathrm{E}(\mathrm{LTE})_{j t}$ is the expected lifetime earnings for a person aged 25 of gender $j$ in year $t$, and $\bar{e}_{i j t}$ the annual earnings for employed individuals in age group $i$ of gender $j$ in year $t$.

Thus, for our sample, there are 100 estimations each of synthetic lifetime years of work, total hours worked and total earnings for someone of age 25, based on gender and a particular year of the CPS and calculation over the 41 age-gender cohorts for that person and ahead of that person. This concept of "expected lifetime outcome" should be thought of as the mean value of each variable in a steady state where the current experience of each cohort is mirrored by all the cohorts that come after it. We will then discuss what the evolving patterns are in these expected outcomes, which of course then makes clear that the states are indeed not steady but rather changing from year to year.

\section{Results}

\section{Descriptive Graphs}

Looking at general trends over the 50-year period under consideration, we plot graphs for both men and women that display the developments in terms of average demographics, individual and labor market patterns over time. ${ }^{10}$ We highlight the results for the sample selection model in the body of the paper with accompanying graphs and also discuss the OLS results, but the OLS graphs are relegated to the appendix.

\footnotetext{
${ }^{10}$ The descriptive graphs are weighted by the person-level weights provided by the CPS data. The graphs based on the regression coefficients are not weighted due the Heckman selection correction estimation not allowing weights in Stata if the two-step command is specified. In practice the weights make little difference and the unweighted descriptive graphs are quite similar to the weighted ones. Also, while we plot these graphs for the entire sample, when we instead restrict them to either labor market participants, non-zero hourly earners or nonzero annual earners, the general patterns remain the same. These alternative graphs are available upon request from the authors.
} 
In Figure 1.1, average education, measured in terms of years of schooling completed, exhibits an increasing trend over time for both men and women, rising from a little over 10 years in 1964 to 14 years of schooling in 2013. While both men and women saw increases in the average years of schooling over the entire time, women had lower levels until the early 2000s, changing after 2001. From that point onwards women have obtained on average more years of schooling than men.

In terms of average potential experience, while both genders exhibit a U-shaped pattern over this time frame, women had more average potential experience than men over the entire period (Figure 1.2). This is driven by the age component as potential experience is derived from age and years of education as outlined in the previous section. Thus women in the workforce are slightly older than men (partly related to their longer average lifespan) and over this time period, the demographics change to favor relatively younger members in the labor force over the middle years, bottoming out in the early 1980s, and subsequently displaying a rising average age (and thus potential years of experience) subsequent to the 1980 s.

However, labor market outcomes-real hourly earnings, real annual earnings and annual hours worked-do not exhibit any cases where women rise above men, or any case of gender reversal as seen in educational attainment. Over the entire time period men receive higher average real hourly earnings (Figure 1.3), higher average real annual earnings (Figure 1.4) and display higher average annual hours worked (Figure 1.5). Men also display significantly more year-to-year variation in earnings and hours worked, while women show a significantly smoother pattern from year to year. This is likely caused in large part by the fact that men have a much higher labor force participation rate (and an employment rate), so they are less likely to adjust their labor supply in response to the business cycle and thus are more subject to fluctuations in labor demand affecting their hours worked and pay.

For women over time, increases in terms of real hourly earnings and real annual earnings are visible and show some narrowing of the gender earnings gap, but it is still a persistent gap (Figure 1.3 and Figure 1.4). In terms of annual hours worked women saw increases in their hours worked, in particular from late 70 s and early 80 s onwards, converging towards the male 
average hours worked. However, still women work fewer hours than men in 2013 by a substantial margin of over 200 hours per year on average (Figure 1.5).

\section{Heckman and OLS hourly earnings regression results}

In our analysis over the 50-year time period we analyze log real hourly earnings and log annual earnings. We find that selection bias plays a large role in our data: for male negative, almost stable, selection is found for these two measures; in other words, men who are in the labor force have unobservable characteristics that are negatively correlated with earnings potential. For women the finding is more striking, but also consistent with the finding of Mulligan and Rubinstein (2008) for the real hourly earnings. Women initially have negative selection until about the late 1980s, thereafter the selection is positive. These results are not echoed identically in annual earnings where women also have negative selection into employment, albeit reducing over time, but only display positive selection at the very end of the period under investigation.

For the experience results we find convergence in returns for increasing potential experience levels for both hourly earnings and annual earnings. For education the results differ for hourly earnings and annual earnings: returns to High School and College are higher for women than for men for hourly earnings. For annual earnings male and female returns to either education level tracked each other and only a higher return for females is found in the later years, after 2008.

Looking at the selection effects over time, Figure 2.1.A displays the degree of selection bias as percentage of log real hourly earnings. The coefficient of the Mills ratio from the hourly

earnings regression multiplied by the average sample Mills ratio is calculated, $\exp \left(\widehat{\rho_{J t}} * \overline{\widehat{\lambda_{J}}}\right)-$ $1) * 100$. The Mills ratio coefficient is always significant at the 1 percent level, indicating that selection is an important factor in our data. For both genders, we plot this number over time: For men we find negative selection bias over the entire period and the effect remains relatively stable in the 15 to 25 percent. This indicates that males in the labor force are negatively selected and they will receive lower hourly earnings than a randomly selected sample. This could potentially be driven both by younger men who work due to not continuing with higher 
education, and by men who do not stop working at later ages, potentially due to lower retirement savings than their more productive peers.

For women the trend is very different, but always above the male levels of negative selection in any given year. In the few early years in the 1960 s, up to 1968 , there is slightly positive selection for women, then negative selection until the late 1980 s and then positive selection which is increasing over time. These trends for women are similar to the results found by Mulligan and Rubinstein (2008), who use the selection correction with marital status interacted with children under the age of 6 . We also find similar results when we mirror these results. ${ }^{11}$ In our case, only using marital status as exclusion restriction, we are able to extend our analysis to the early 1960s and up to 2013. Contrary to Mulligan and Rubinstein (2008), we find a positive selection in the early years of 1960s, where they do not have the data, and a strong increase in positive selection after 1999 , which is their cut-off in their analysis. For women in the beginning of the 1990s, 5 to 10 percent of their hourly earnings can be accounted for by positive selection. In the late 2000s, particular around the economic recession, 20 to 60 percent of hourly earnings can be accounted for by positive selection. However, this peak declines about 40 percent in 2013. Demographic changes and the composition of women selecting into the labor force could partially account for these trends and changes in the selection. This is one of the most interesting findings from our research and is consistent with an increasing trend towards potential high earners among women being more likely to both marry and continue working.

We wanted also to see whether our models fit relatively better or worse over time. In particular, we were concerned that a regression specification that is fit to data available in 1964 might no longer be relevant by 2013 . While a simple measure of fit would be the R-squared, this is not calculable for selection models (we do show the R-squared measure for our OLS models in Appendix Figure A.1.1). Hence in Figure 2.1.B, to try to ascertain goodness of fit, we instead plot the year-to-year correlation of individual predictions from our Heckman model and

\footnotetext{
${ }^{11}$ Results are available upon request from the authors.
} 
the actual observed levels of outcomes for hourly earnings. We find a positive correlation that is slightly increasing over time, implying that our models fit no more poorly over time even though they are based on a stable specification, and if anything, actually work better for the more recent period (a similar pattern obtains for the OLS results as measured by the R-squared, as shown in Figure A.1.1.). For men the correlation between predicted and observed outcomes is always higher than it is for women.

We now turn to taking a closer look at the underlying trends in the returns to (potential) experience and education for men and women over the entire time period. Given the nonlinear specification for returns to potential experience, we show the marginal returns to an additional year of potential experience at different points in the function and compare these across time and by gender.

Figure 2.2 shows the marginal returns at different levels of experience, 5, 10, 15 and 20 years respectively, for both genders. ${ }^{12}$ These are based on the Heckman selection-corrected hourly earnings regression with the dependent variable in log real hourly earnings. The lines display the average marginal effect of the years of potential experience in percent of (level) hourly earnings. In addition, we show with bars around each line the 95 percent confidence intervals for the estimates.

Across all the years of experience it is possible to see that the male average marginal effects are usually above the female marginal effects, indicating higher returns for men than women. However, for the different years of experience different degrees of convergence and even coincidence at the same level for both male and female returns are visible.

In Figure 2.2 the average marginal returns to 5 years of experience for males are above the ones for females and no convergence is apparent. Also the variances of the results for both

\footnotetext{
${ }^{12}$ We also estimated returns to 25 years of experience, but these graphs look quite similar to those for 20 years experience and thus we have dropped them from the paper for brevity; they are available from the authors upon request.
} 
men and women, as shown by the 95 percent confidence interval bars, are large. But a large decrease in the variance occurs between 5 and 10 years of experience. This variance continues to decrease with higher levels of years of experience. For 10 years of experience one can see already a narrowing of the returns for men and women over time, the lines converging towards each other but with a gender gap remaining in the returns. Men in 2013 increased their earnings by 0.8 percent of hourly earnings if they increased their experience from 9 to 10 years while average marginal return for women was only 0.4 percent of hourly earnings.

The average marginal returns to 15 years of experience show a convergence of male and female return at the end of the period and in the 2000s coinciding even. Men and women have almost the same returns of 0.5 percent of hourly earnings from moving from 14 to 15 years of potential experience.

The returns for 20 years of experience are almost identical in terms of patterns to the 15 years of experience figure and also show a convergence and coincidence at the end of the period. The marginal returns for men and women are 0.2 percent of hourly earnings. ${ }^{13}$

Comparing the above Heckman selection-corrected results for returns to experience with the OLS results (Appendix Figure A.1.2), it is possible to see that the two main general patterns remain: male returns being higher than female returns in general and the decreasing variance. However, the figures showing higher than 5 years of experience and up to 20 years of experience exhibit convergence in the marginal returns for men and women. And, contrary to the Heckman selection corrected graphs, the OLS graphs of the returns do not converge to close the gender gap entirely for 15 and 20 years of potential experience.

\footnotetext{
${ }^{13}$ In Figure 2.2 the use of potential experience overstates actual experience, and more so for women than for men. The coefficients do not only represent returns to experience but a combination of returns to experience and other forms of human capital investment. Following Mincer (1974) lower rates of investment might be the reason for the narrowing in gender differences with higher experience levels. Given that over time actual experience of women relative to men has risen while potential experience has remained relatively constant, one concern is that the potential experience coefficients might be biased if earnings are based on actual experience instead of potential experience.
} 
We turn now to the Heckman results for the returns to education of high school completion and college completion (Bachelor's degree). As shown in Figure 2.3, the female marginal return to high school completion is above that of the male return and increasing since the late 1980s. The male returns are almost flat at about 20 to 25 percent higher hourly earnings for moving from no high school diploma to high school completion. For women these returns have increased from 25 percent to 55 to 60 percent higher hourly earnings in 2012 and 2013.

For college graduate women always have a higher marginal effect of college completion than men, and from the late 1980s the gender gap in favor of women widens (of course this is still relative to a lower base earnings for less educated women relative to men). While in 1964 women were able to increase their hourly earnings by 60 to 70 percent with the additional educational attainment of a bachelor degree or above, women at the end of the period during the years 2010 to 2013 almost increased their hourly earnings by 115 to 125 percent. For men, college completion compared to high school completion increased their hourly earnings by 30 percent in 1964 and by 75 percent in 2013.

While the OLS and Heckman selection corrected graphs are very similar in general trends for the various levels of experience, the returns to education results differ substantially. The OLS graphs (Appendix Figure A.1.3) for the returns to high school and college do not exhibit the same diverging pattern of men and women as the Heckman results. In fact it seems that the marginal effects for both seem to coincide and evolve fairly similarly, and generating the different result that men's relative returns to college education rise above women's returns by the end of the period.

This in turn points to the fact that selection seems to be an important element in the hourly earnings regression for log real hourly earnings, changing the calculated returns to education significantly when accounting for selection into the labor force. Without accounting for selection, the returns to education are actually understated, particularly for women. 
We also consider total earnings in our analyses to allow for the effects of changing hours as well as changing hourly earnings. Using the log real annual earnings as the dependent variable in our total earnings analysis (but again converting all our results to show effects on levels), we find results that are different for the selection effects estimations over time than when using log hourly earnings (Figure 2.4.A). For women, in particular, a negative selection effect is present over almost the entire time period until 2009, with decreases starting in the late 1980s. From 2009 onwards a sharp increase occurred and the selection effect turns positive, coinciding with the economic crisis period. The selection effect for men is still negative as with the log hourly earnings but decreases since the late 1980 s and becoming less negative. The reduction in negative selection effect eventually turning to positive indicates that the women with lower earnings potential were both more likely to work and much more likely to work more hours, but that this effect was eradicated on both fronts over time as women with higher earnings potential increasingly became more likely both to work at all and also to work more hours. For men, the hours effect is apparently minimal in terms of change over the period, but again implies that negative selection occurs both in terms of likelihood of working and in terms of likelihood of working more hours (but that the hours selection effect is dominated by the participation selection effect, as the graph is not that different from Figure 2.1A for men).

In terms of correlation between actual and predicted annual earnings from the Heckman model men have a higher correlation than women over the entire period. However, over time these correlations for both genders decline slightly and then increase again (Figure 2.4.B) with a higher correlation in the earlier years, perhaps due to less hours variation in the population in the earlier part of the sample period.

The average marginal effect for returns to experience for the various years of experience, 5 to 20 (in intervals of 5 years), exhibits almost an identical pattern to the hourly earnings results: the variance decreases over time, male returns are above female returns in general but convergence and almost full coincidence in returns as a percent of earnings occurs for the 15- 
20 years of experience (Figure 2.5). The magnitudes in terms of percentages tend to be somewhat smaller than for the hourly earnings.

For the log annual earnings we also estimated these OLS returns to experience for different years and found that albeit male returns are above female returns a convergence over time. ${ }^{14}$ The results for 5 to 20 years of experience show a convergence. For 20 years of experience the returns for male and females in the later years of our time period coincide. An anomalistic result in the OLS results were negative returns for women at the 5 years of potential experience level, which indicate the need for correcting for selection into the labor force to obtain believable returns to work experience (and thus another grounds for preferring the selectioncorrected estimates over the OLS estimates).

Comparing the returns to high school and college for the Heckman selection-corrected estimates of annual earnings, we find that the patterns for annual earnings are consistent with the hourly earnings in later years (Figure 2.6). Women achieve higher returns to high school and college than men starting from 2001. In the hourly earnings they started to achieve this earlier in time and a larger gap between the genders was visible. For annual earnings the returns for men and women closely track each other and then diverge after the economic crisis in 2008, with women then receiving higher returns to high school and college completion. Thus partly the difference in these patterns are likely due to differential changes in the hours worked over time, with women steadily increasing their hours worked from the mid-1980s onward.

The OLS results for annual earnings follow the OLS patterns observed for the hourly earnings and are dissimilar to the Heckman results. This again points towards the issue that selection is an important component of the picture in order to understand the actual returns to educational attainment for men and women over time.

\footnotetext{
${ }^{14}$ These OLS graphs and results for annual earnings are available upon request from the authors.
} 


\section{Synthetic worklife graphs}

We turn now to our synthetic worklife calculations to see if convergence occurs in these calculations. Overall, synthetic, or expected, worklives for women, in terms of years in work, their earnings and hours worked over their lifetime, have converged towards men's worklives.

In Figure 3.1, female expected lifetime years in work (as defined in Section III above) are increasing over the 50-year period of our data while male expected lifetime years in work are slightly decreasing from above 35 years in work lifetime expectation in 1964 to 30 years in lifetime work in 2013. Contrary to this, female expectations rose steadily from 15 years of lifetime work expectation in 1964 to over 25 years of expected lifetime work in 2013, thereby narrowing the gap between genders.

In addition to increased expectations of lifetime years in work, women expect to accumulate more hours worked over their lifetime while men have not seen a comparable increase, maybe even a slight decrease, in their expected lifetime hours worked. This leads to a narrowing of the gender gap in expected lifetime hours worked for men and women (Figure 3.2.).

Not only have expectations of lifetime years in work and expected life hours worked increased, but women have also increased over time their lifetime expectation regarding total earnings, almost doubling from 1964 to 2013. Men over the same time period have also increased their expected lifetime earnings, but across the entire period have consistently had much higher expected lifetime earnings. While there is some convergence of the female and male expected lifetime earnings, the gap does not seem to have narrowed much (Figure 3.3).

This last pattern reflects the continued gap in hourly earnings as well as a continued difference in hours worked; thus notably the increased attachment of women to the labor force in terms of both participation and hours worked does not appear to have paid off fully in terms of closing the lifetime earnings gap. These synthetic calculations thus underscore both the convergence in male and female patterns and the continued inequalities underlying those patterns as full convergence is yet to be achieved. 


\section{Conclusion}

The patterns that we show and discuss in this paper indicate that there has been significant convergence over this fifty-year period in the work lives of women and men, but that differences continue. We have emphasized the commonality of women's (and men's experiences) by focusing on average returns. But perhaps the most notable change over this period is the rising effect and switch from negative to positive selection into work in the case of women, which implies that those women who profit most from paid work participation are increasingly likely to be found in it. This is also reflected in the differences between the OLS and sample selection-corrected results for returns to education.

Interestingly, returns to potential work experience do converge for women and men in both OLS and sample-selection-corrected results for those with more years of potential experience. This convergence is thus not observed for all workers but does affect those with longer potential labor market attachment. And again, given that women still make less than men at the lowest levels of experience (and education), this also still implies lower absolute returns to working for pay for women than for men.

In our year-by-year calculations of expected lifetime labor attachment and earnings for young persons starting out on their worklives, these indicate again convergence by gender in worklife patterns, but less convergence in recent years in lifetime earnings. The interesting question here in part is what causes the evolution of expected values of lifetime labor attachment and earnings. This is clearly not a steady state situation, and thus, particularly given the relatively smooth evolution of the expected values, one might look for causes of this evolution that have also evolved relatively smoothly. Possibilities include demographic changes of a smooth but changing nature, including rises in the age at first marriage, drops in lifetime fertility, and increasing lifespans for both women and men. These changes could have effects on human capital investment decisions (both education and work experience) both directly on cohorts and indirectly through their effects on prior cohorts (and thus affect younger cohorts through changing their expectations of what will happen over their lifespan). We expect our future 
research agenda will explore the determinants of this evolution of expected values and also how expected values differ from the actual values that the cohorts experience.

This line of research is meant to complement rather than supplant the more recent research focus on divergence in outcomes within women and within men taken as groups. Our research focuses more on commonality of outcomes for women and for men to consider how larger trends in gender differences can also be seen in these average results and to remind us of the primacy of gender as a factor of interest and in determining life's outcomes. 


\section{References}

Autor, David H., Lawrence F. Katz, and Melissa S. Kearney. 2008. "Trends in U.S. Wage Inequality: Revising the Revisionists." The Review of Economics and Statistics, 90(2): 300-323.

Bacolod, Marigee P. and Bernardo S. Blum. 2010. "Two Sides of the Same Coin: U.S. "Residual" Inequality and the Gender Gap." The Journal of Human Resources, 45(1): 197-242.

Blau, Francine D. and Lawrence M. Kahn. 2000. "Gender Differences in Pay." Journal of Economic Perspectives, 14 (4): 75-99.

Blau, Francine D. and Lawrence M. Kahn. 2005. "Changes in the Labor Supply Behavior of Married Women 1980-2000." NBER Working Paper 11230.

Blau, Francine D. and Lawrence M. Kahn. 2006. "The U.S. Gender Pay Gap in the 1990s: Slowing Convergence." Industrial and Labor Relations Review, 60( 1 ): 45-66.

Fernández, Raquel. 2013. "Cultural Change as Learning: The Evolution of Female Labor Force Participation over a Century." The American Economic Review, 103(1): 472-500.

Goldin, Claudia. 2014. “A Grand Gender Convergence: Its Last Chapter.” The American Economic Review, 104(4): 1-30.

Goldin, Claudia and Solomon W. Polachek. 1987. "Residual Differences by Sex: Perspectives on the Gender Gap in Earnings." The American Economic Review, 77(2): 143-151.

Heckman, James J. 1979. "Sample Selection Bias as a Specification Error." Econometrics, 47(1):153-161.

Heckman, James J. 1980. "Sample Selection Bias as a Specification Error with an Application to the Estimation of Labor Supply Functions." In J. Smith (ed.) Female Labor Supply: Theory and Estimation, Princeton University Press, 206-248. 
Joshi, Heather and Hugh Davies. 2002. "Women's income over a synthetic lifetime." In E.

Ruspini and A. Dale (ed.) The Gender Dimension Of Social Change: The contribution of dynamic research to the study of women's life courses, The Policy Press, 111-131.

King, Miriam, Steven Ruggles, J. Trent Alexander, Sarah Flood, Katie Genadek, Matthew B. Schroeder, Brandon Trampe, and Rebecca Vick. 2010. Integrated Public Use Microdata Series, Current Population Survey: Version 3.0. [Machine-readable database]. Minneapolis: University of Minnesota.

Lemieux, Thomas. 2006. "The "Mincer Equation" Thirty Years After Schooling, Experience and Earnings." In S. Grossbard-Shechtman (ed.) Jacob Mincer, A Pioneer of Labor Economics, Springer Verlag, 125-145.

Mincer, Jacob. 1974. Schooling, Experience and Earnings. National Bureau of Economic Research, Columbia University Press, New York and London.

Mincer, Jacob and Solomon W. Polachek. 1974. "Family Investments in Human Capital: Earnings of Women" Journal of Political Economy, 82( 2): 76-108.

Mulligan, Casey B. and Yona Rubinstein. 2008. “Selection, Investment and Women's Relative Wages over Time." The Quarterly Journal of Economics, 123(3): 1061-1110.

O'Neill, June and Solomon W. Polachek. 1993. "Why the Gender Gap in Wages Narrowed in the 1980s." Journal of Labor Economics, 11(1): 205-228.

O’Neill, June. 2003. "The Gender Gap in Wages, circa 2000." The American Economic Review, 93(2): 309-314.

Polachek, Solomon W. 1975a. "Potential Biases in Measuring Male-Female Discrimination." The Journal of Human Resources, 10(2): 205-229.

Polachek, Solomon W. 1975b. "Differences in Expected Post-School Investment as a Determinant of Market Wage Differentials." International Economic Review, 16(2): 451-470. 
Polachek, Solomon W. and John Robst. 2001. "Trends in the Male-Female Wage Gap: The 1980s Compared with the 1970s." Southern Economic Journal, 67(4): 869-888.

Polachek Solomon W. 2006. "How The Life-Cycle Human-Capital Model Explains Why The Gender Wage Gap Narrowed." In F.D. Blau, M.C. Brinton and D.B. Grusky (ed.) The Declining Significance of Gender?, Russel Sage Foundation, 102-124.

U.S. Dept. of Commerce. 2011. "Education and Synthetic Work-Life Earnings Estimates." American Community Survey Reports, AC-14. 


\section{Figures}

\section{Descriptive Results}

Figure 1.1: Average Education by Gender, 1964-2013

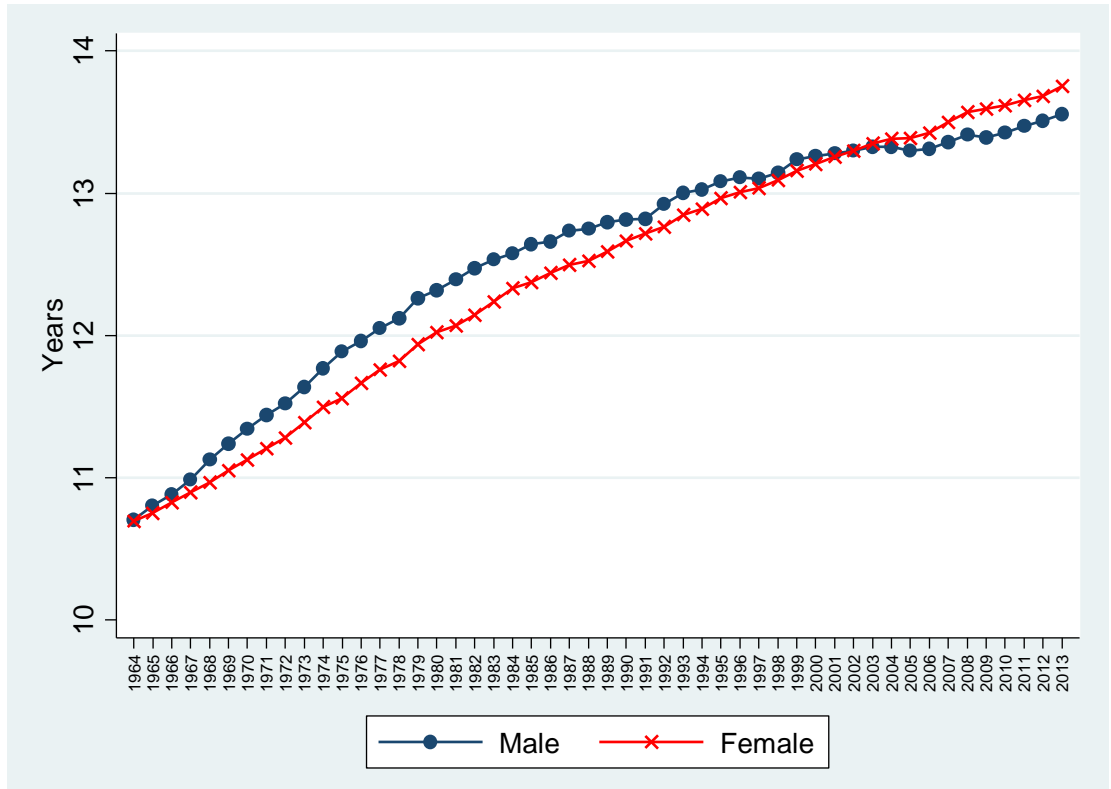

Figure 1.2: Average Potential Experience by Gender, 1964-2013

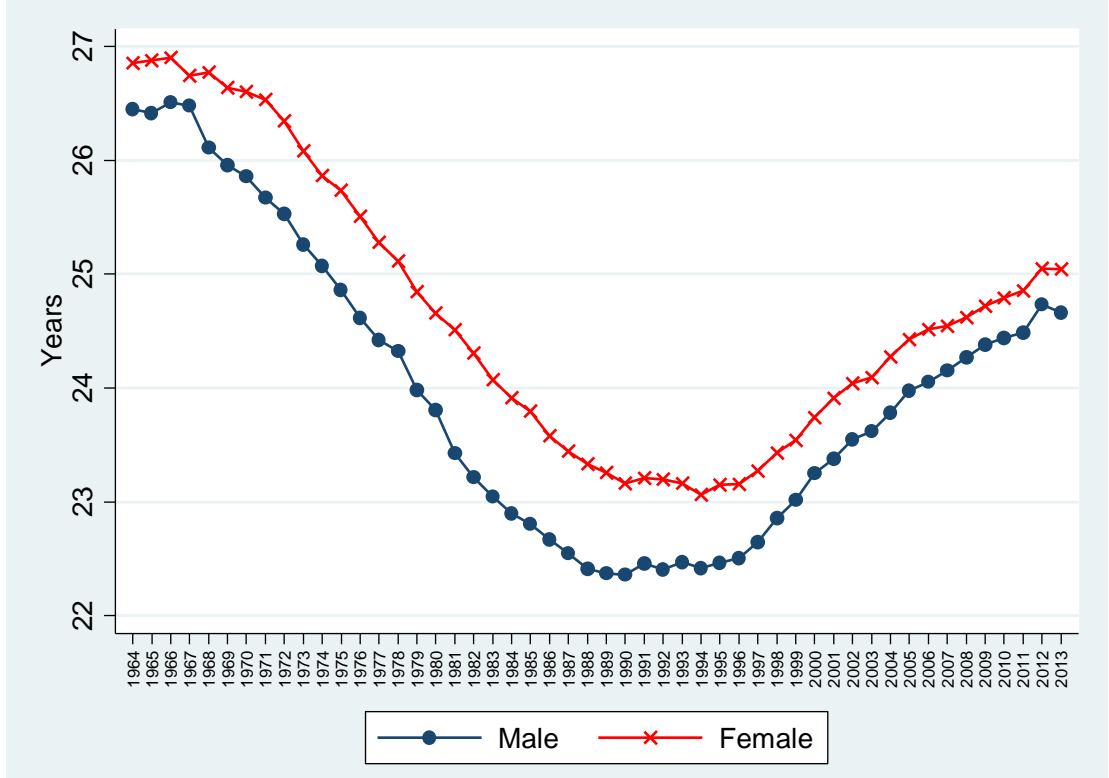


Figure 1.3: Average Real Hourly Earnings by Gender, 1964-2013

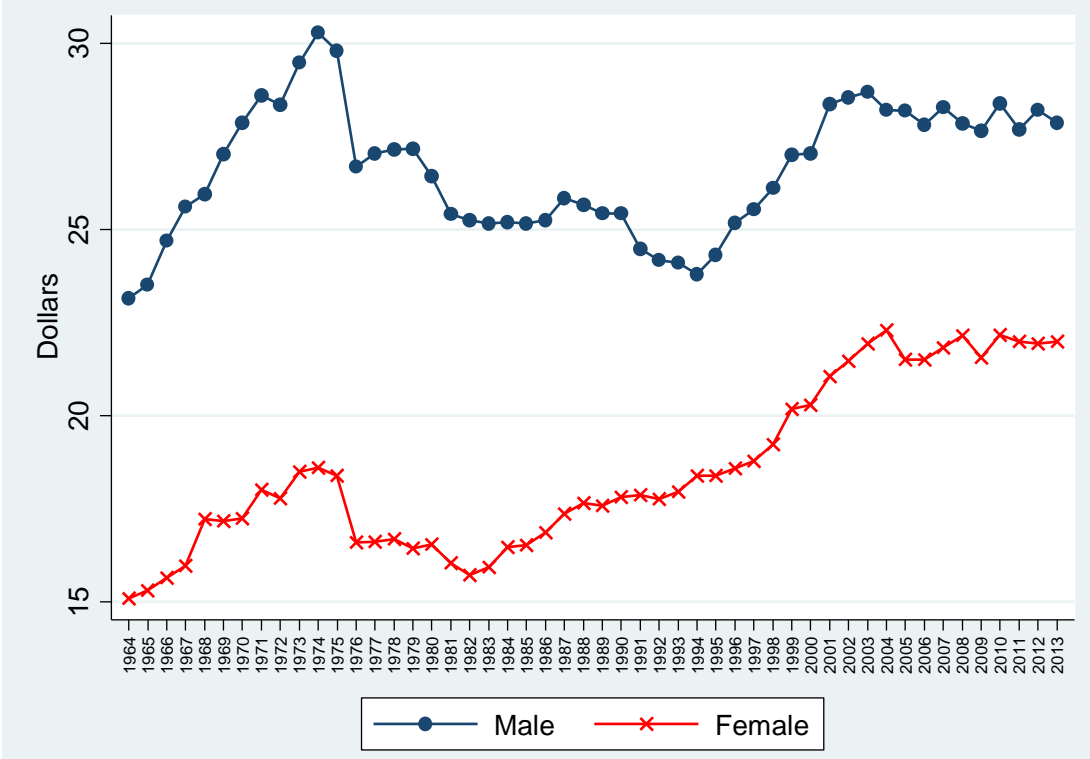

Figure 1.4: Average Real Annual Earnings by Gender, 1964-2013

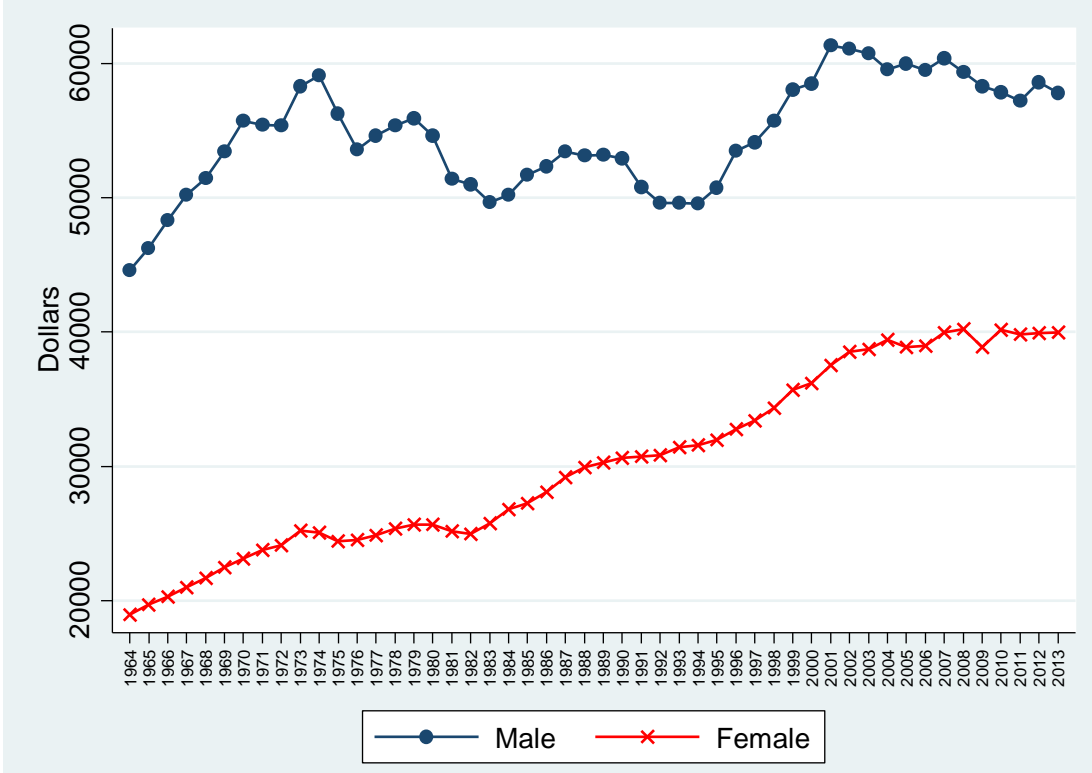


Figure 1.5: Average Annual Hours Worked by Gender, 1964-2013

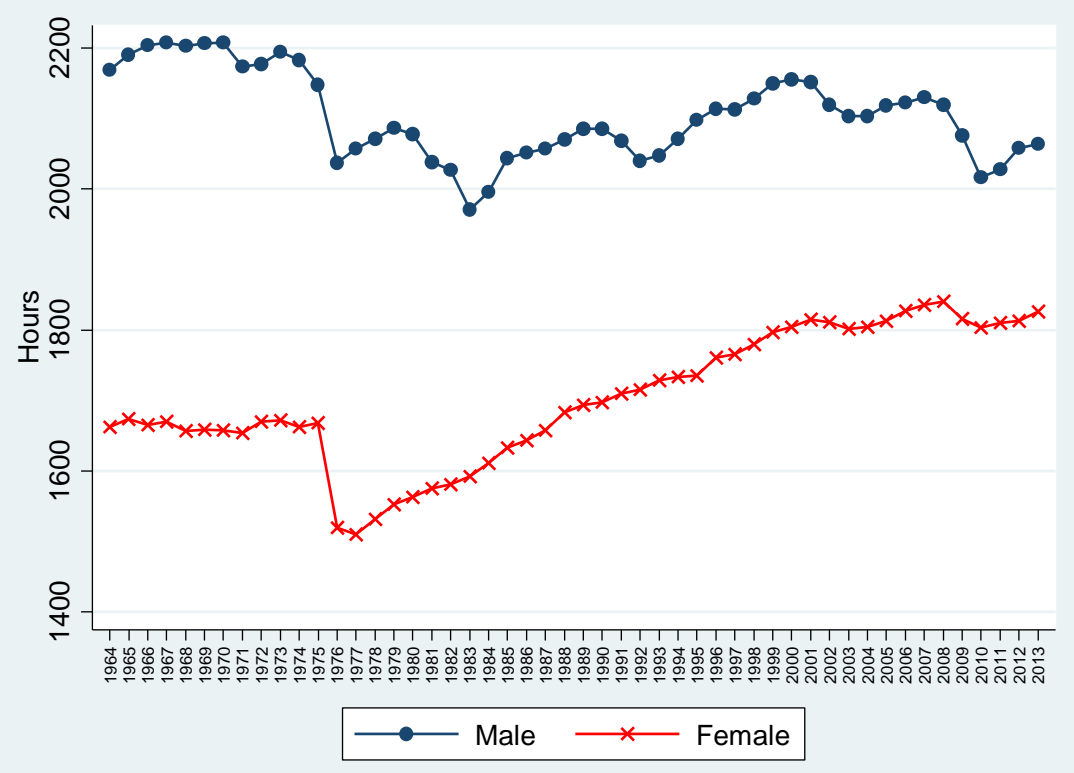




\section{Heckman Selection Corrected Graphs}

Figure 2.1.A: Selection: Mills effect in percentage, log real hourly earnings

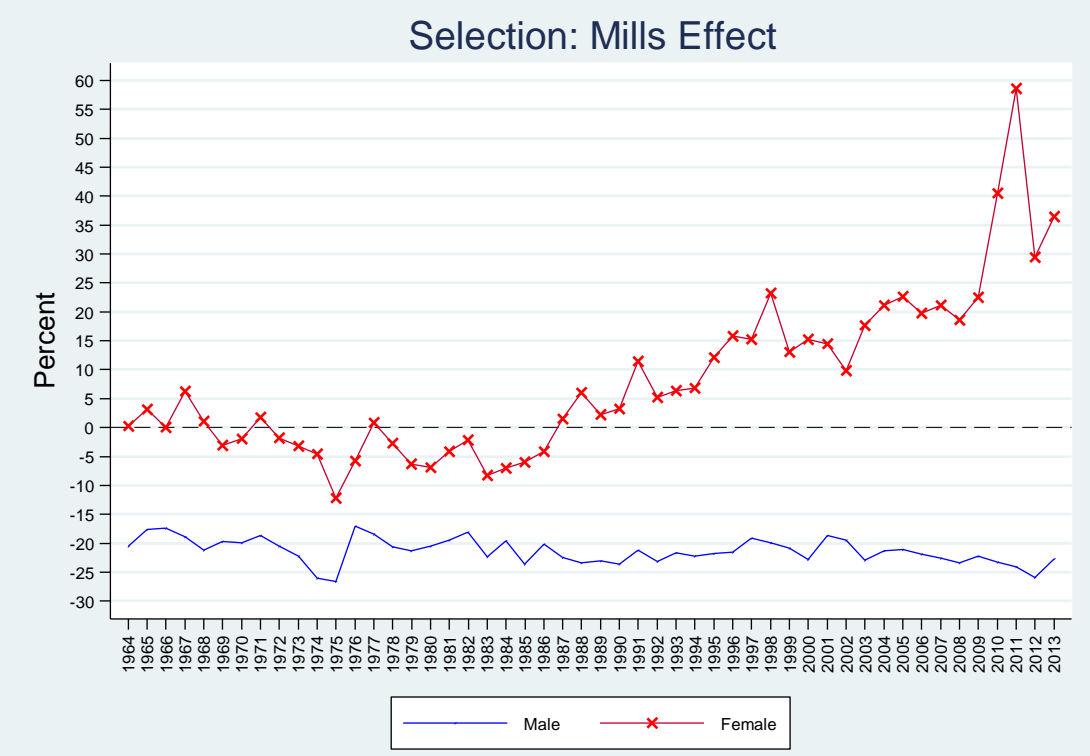

Figure 2.1.B: Correlation: actual and predicted, log real hourly earnings

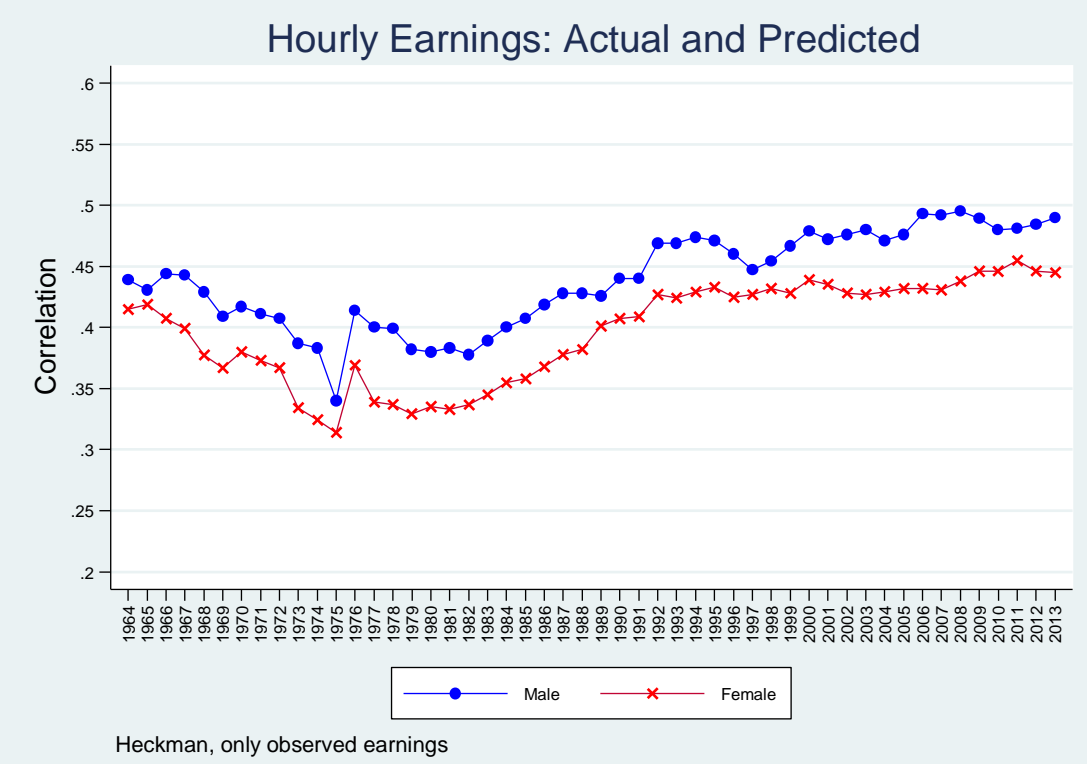


Figure 2.2: Heckman, experience, log real hourly earnings
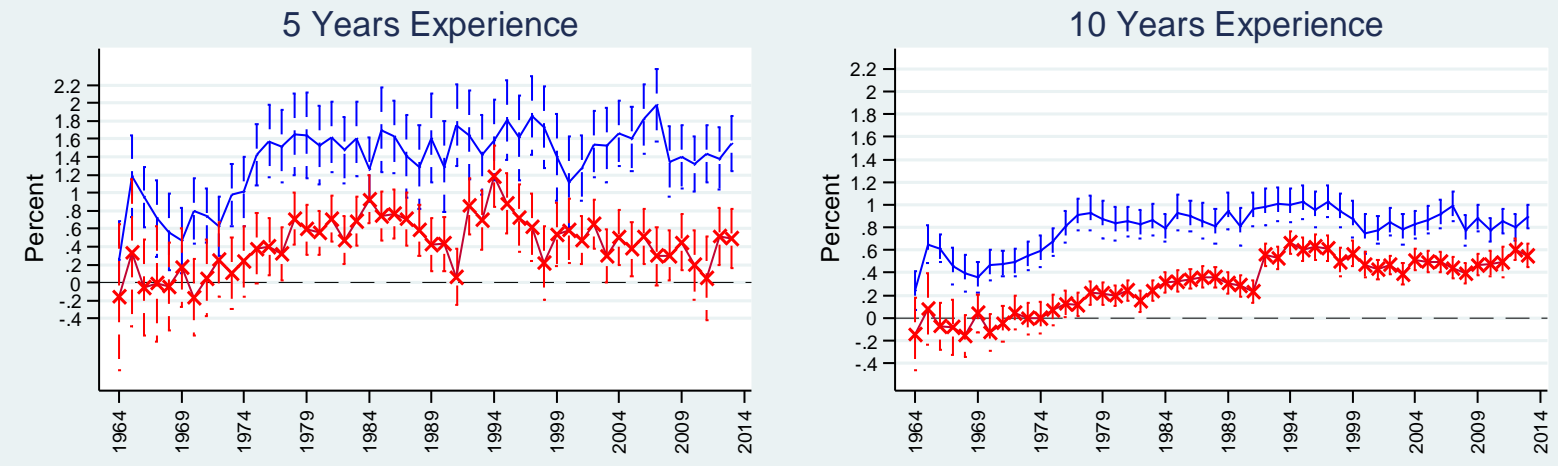

15 Years Experience
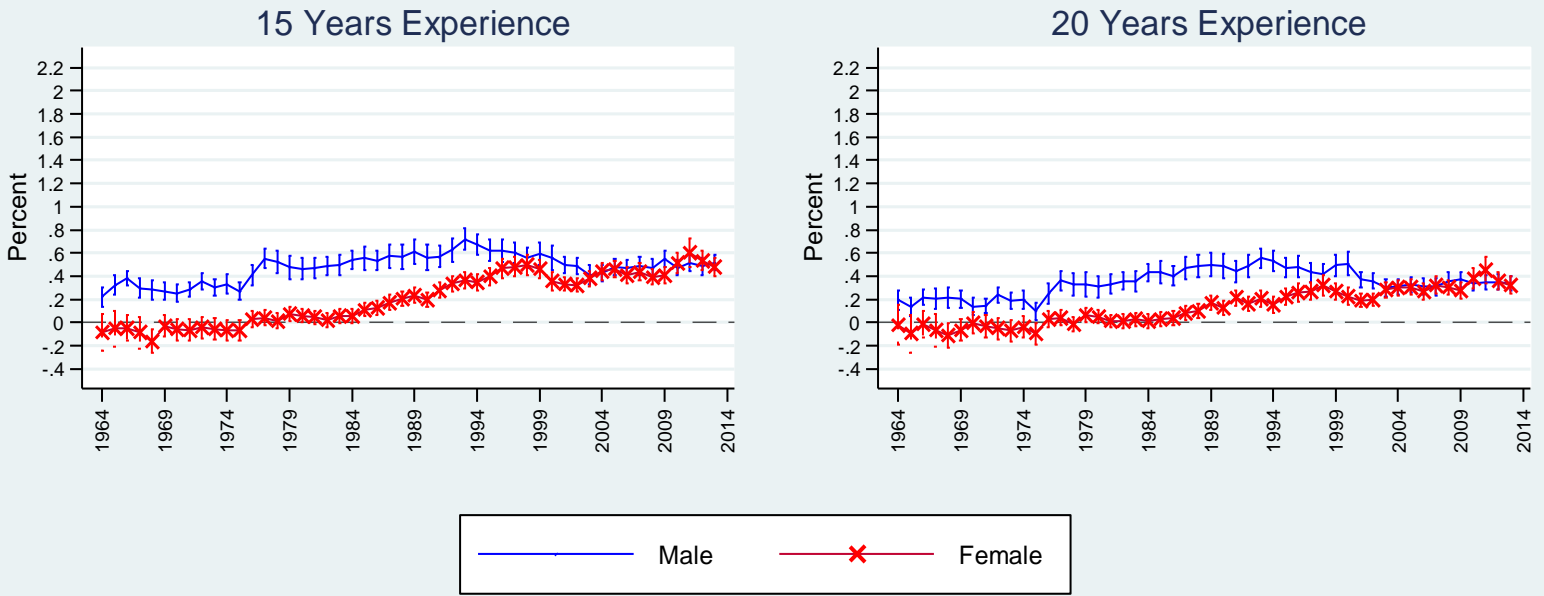
Figure 2.3: Heckman, education, log real hourly earnings
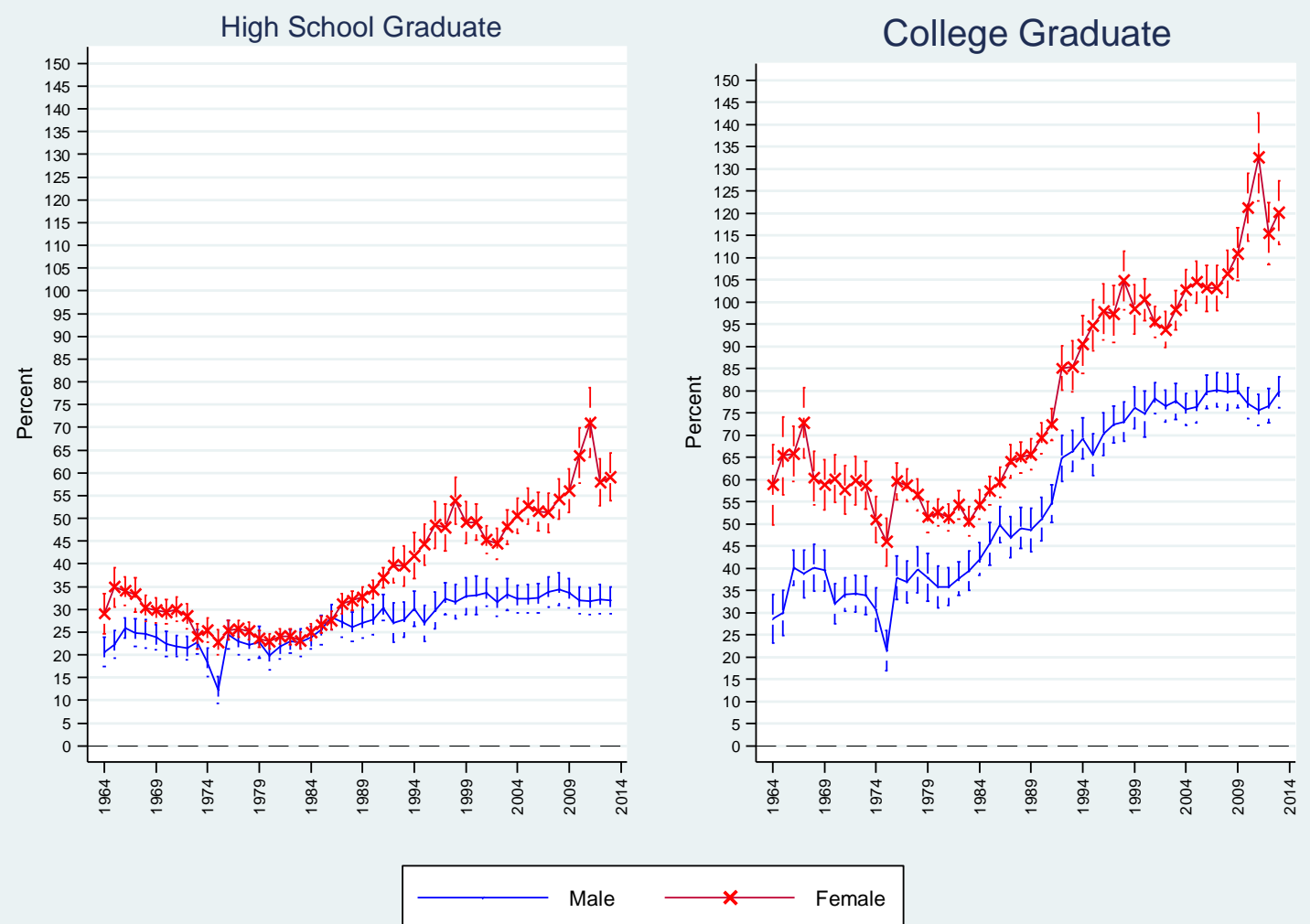

Note: Marginal Effect, Heckman 
Figure 2.4.A: Selection: Mills effect in percentage, log real annual earnings

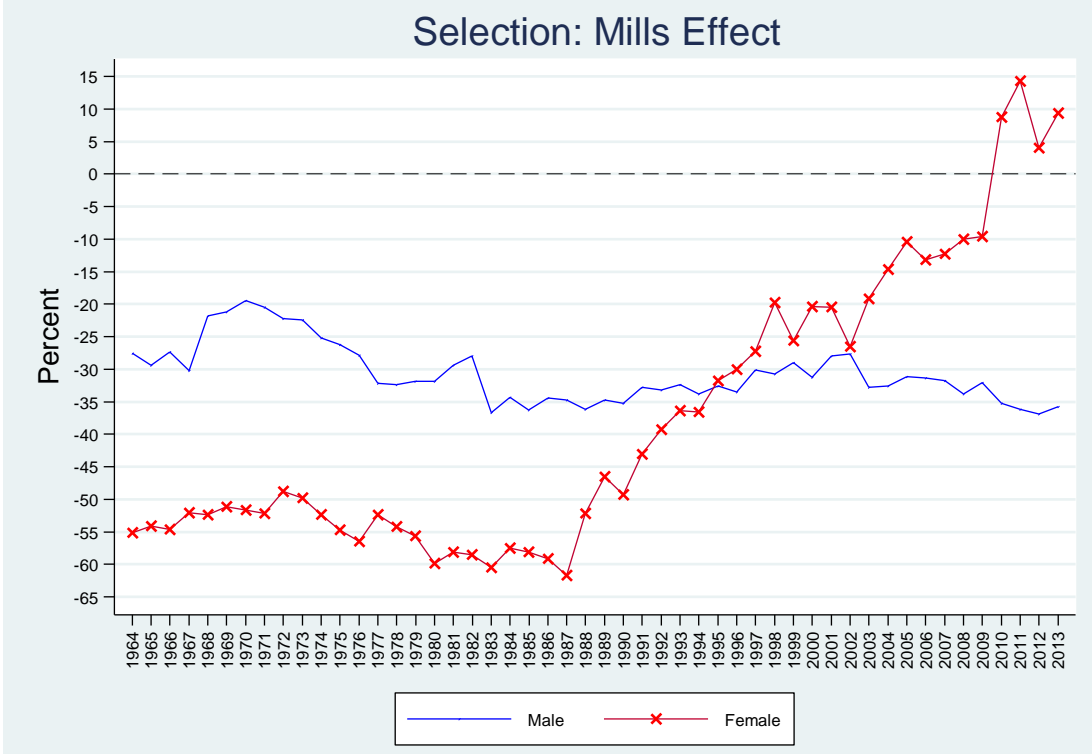

Figure 2.4.B: Correlation: actual and predicted, log real annual earnings

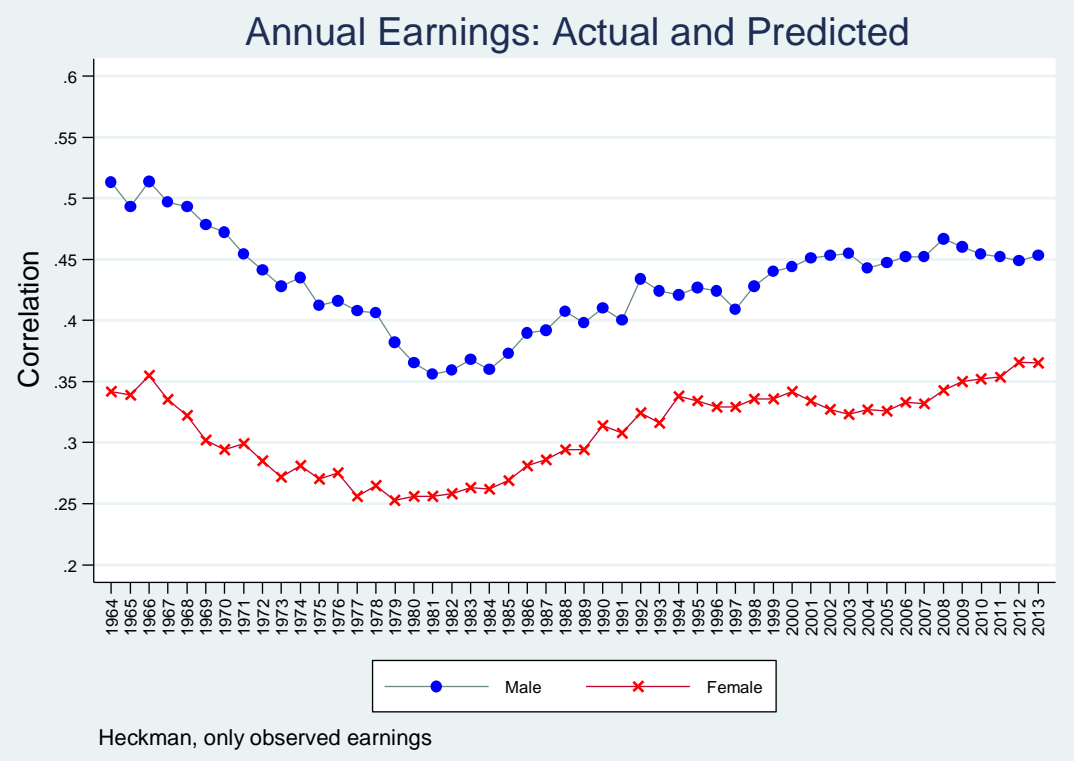


Figure 2.5: Heckman, experience, log real annual earnings

5 Years Experience

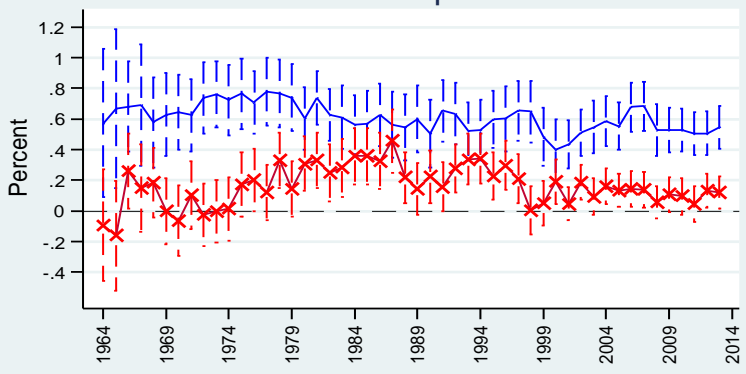

15 Years of Experience

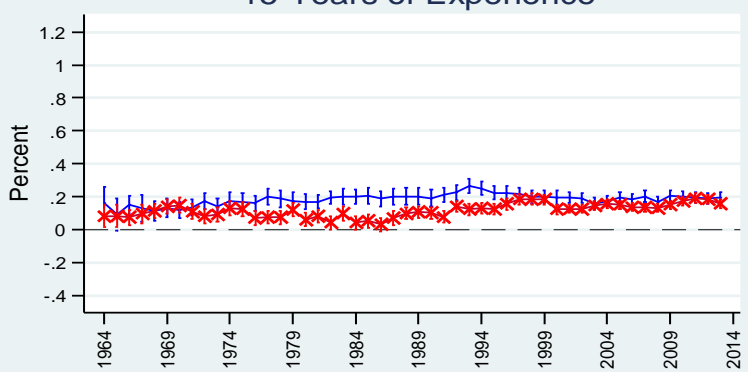

10 Years Experience

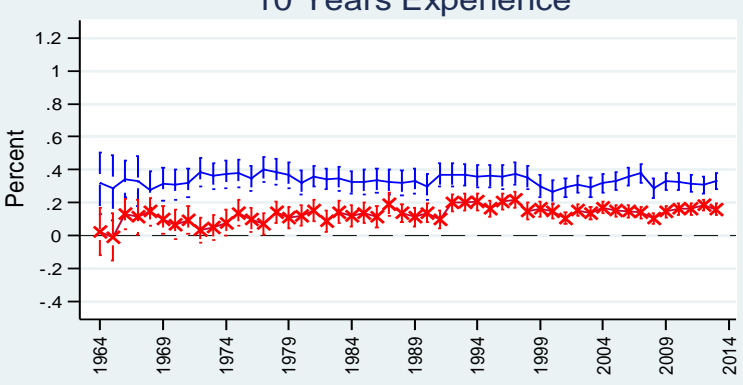

20 Years Experience

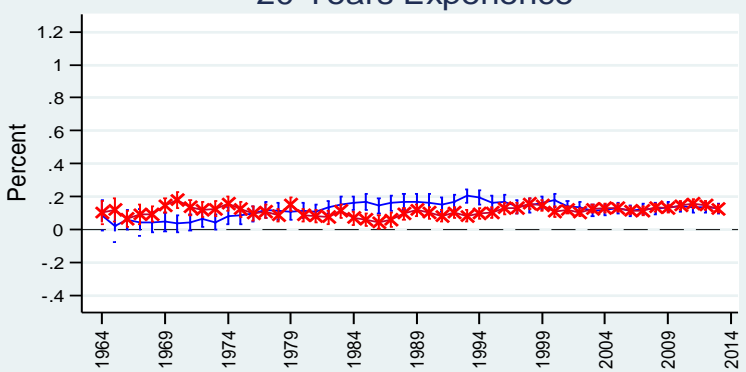

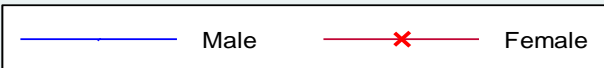


Figure 2.6: Heckman, education, log real annual earnings
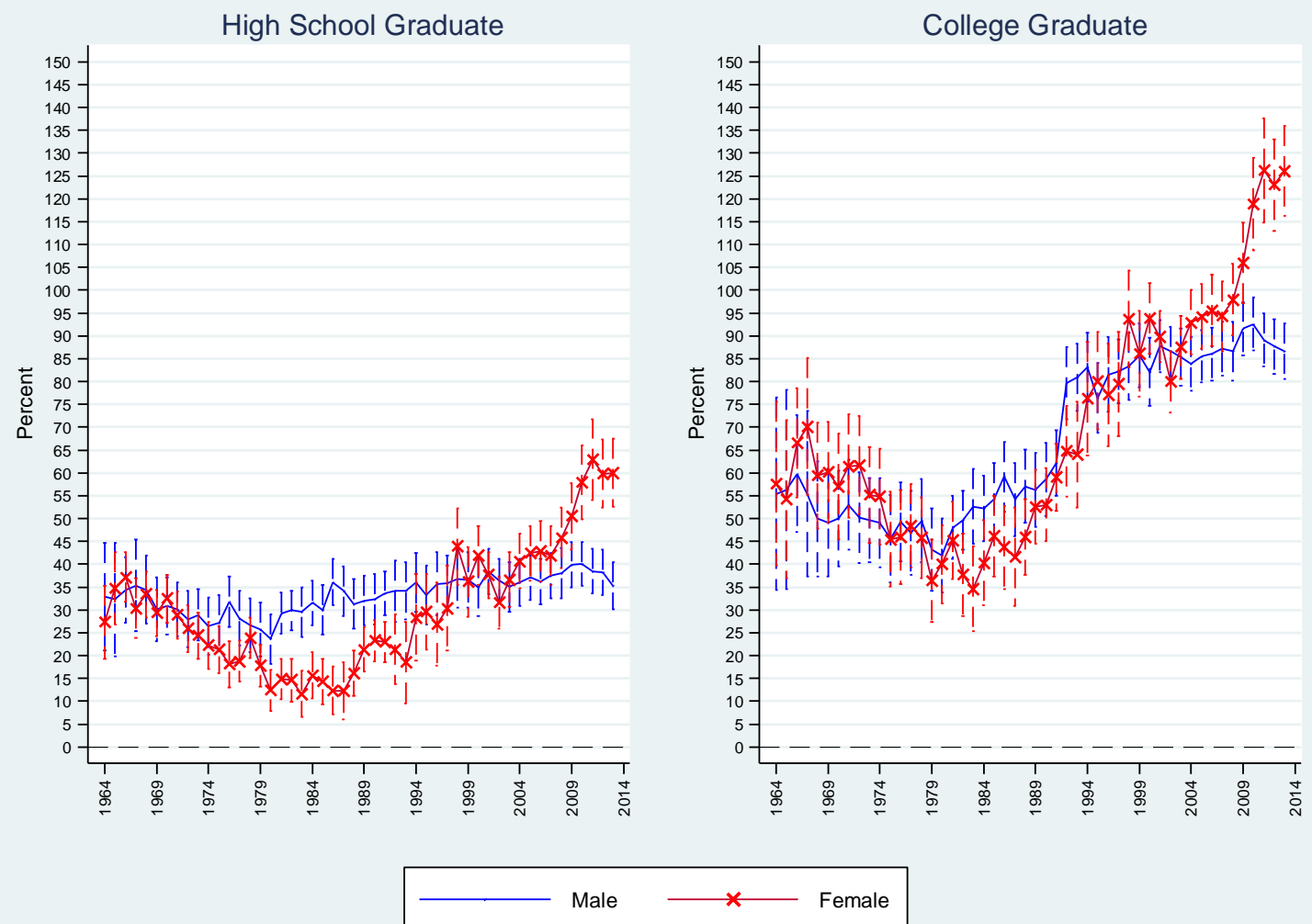

Note: Marginal Effect, Heckman 


\section{Lifetime Graphs}

Figure 3.1: Expected Lifetime Years in Work by Gender, 1964-2013

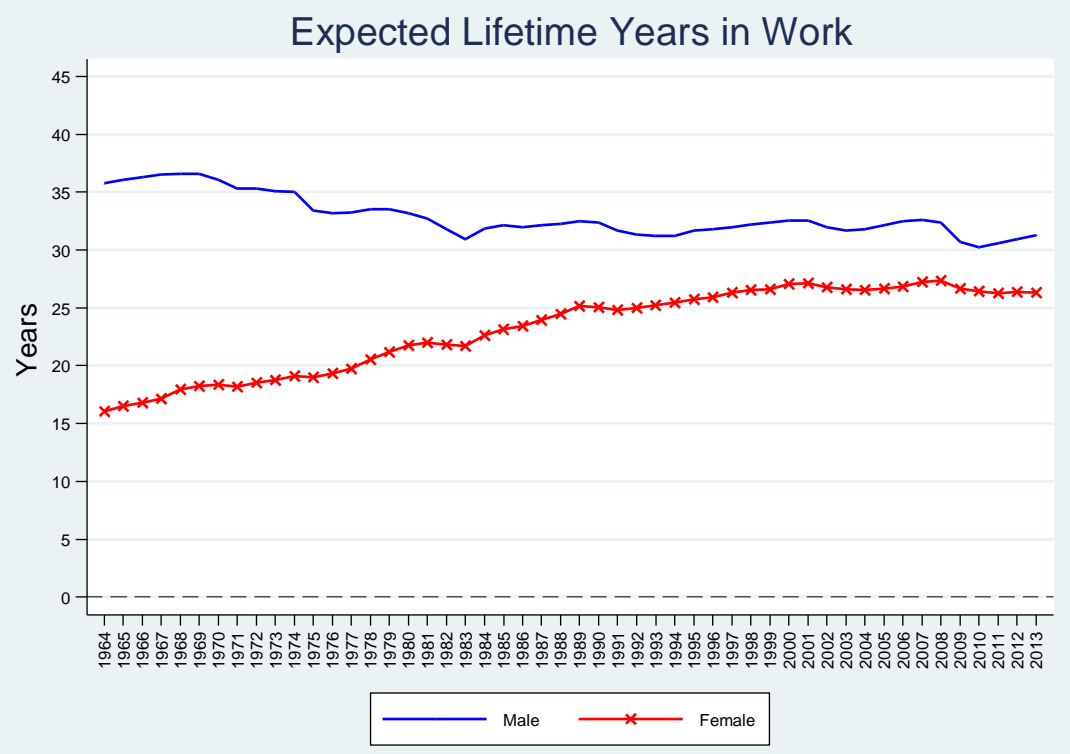

Figure 3.2: Expected Lifetime Hours worked by Gender, 1964-2013

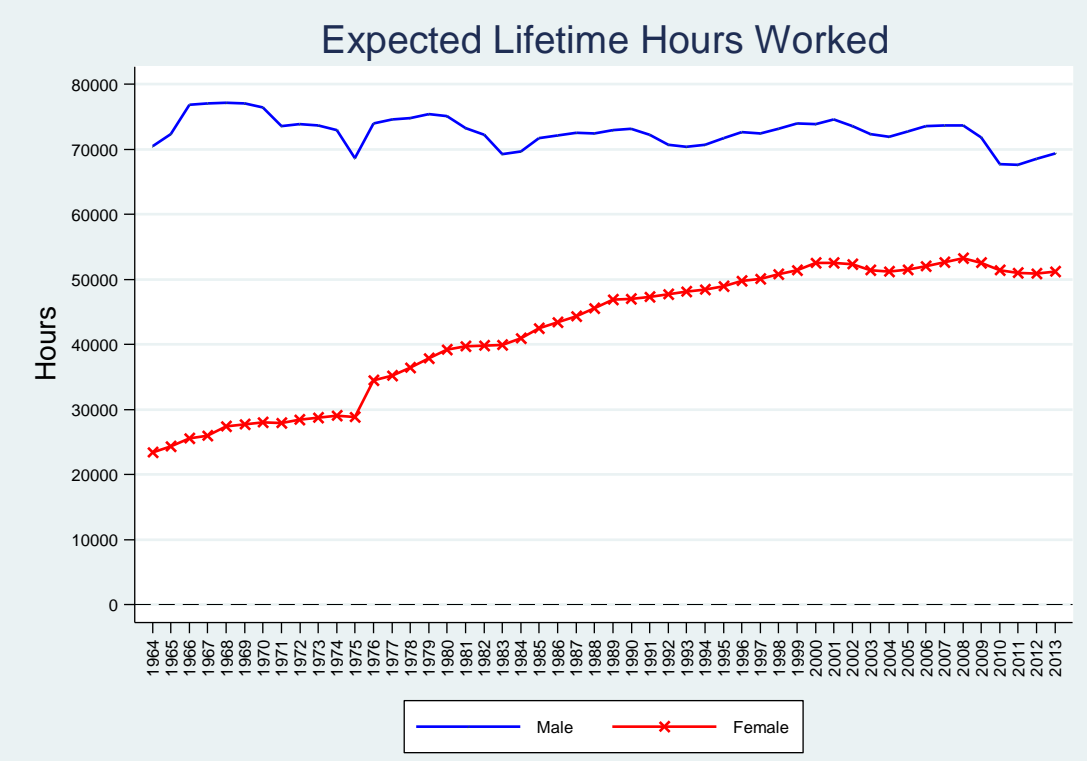


Figure 3.3: Expected Lifetime Earnings by Gender, 1964-2013

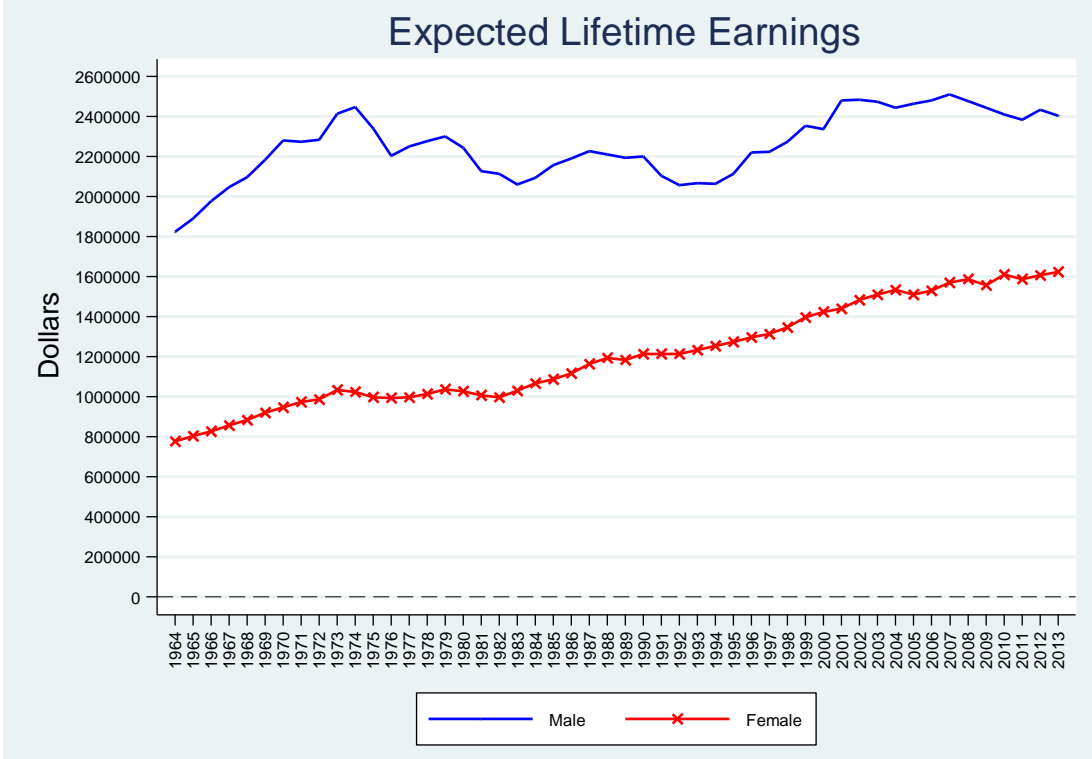


Annex 1: OLS Results, log real hourly earnings

A.1.1: OLS Goodness of Fit, log real hourly earnings

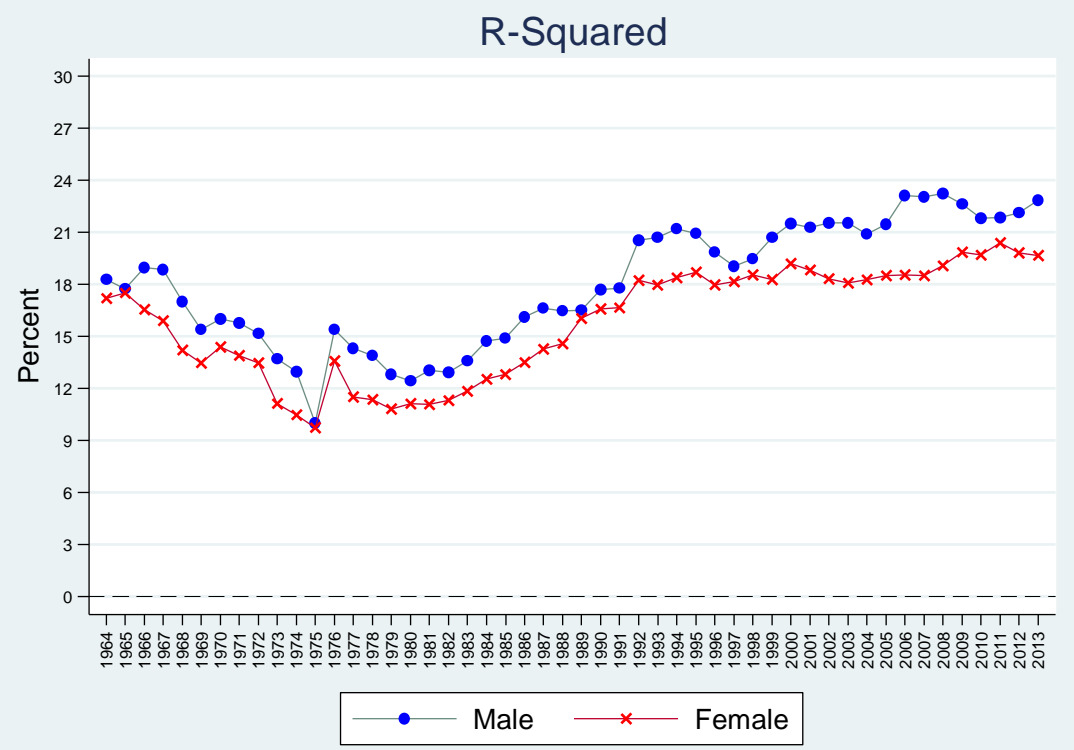




\section{A.1.2: OLS, experience, log real hourly earnings}
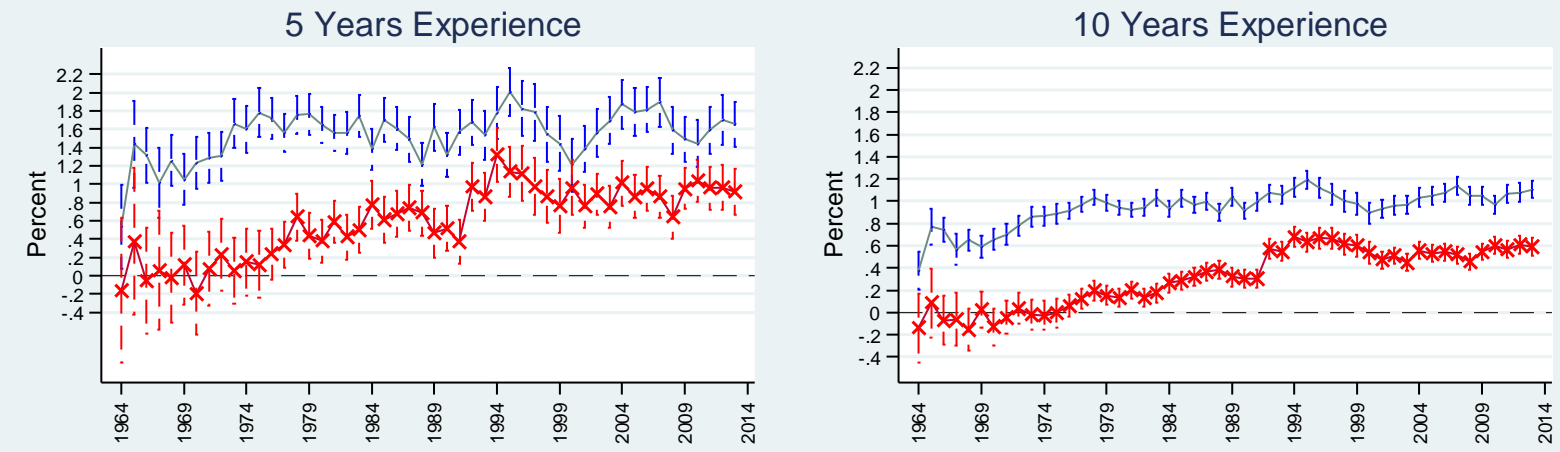

15 Years Experience

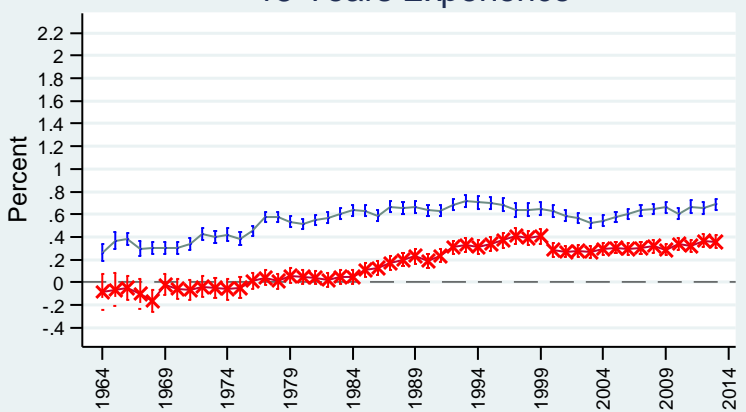

20 Years Experience

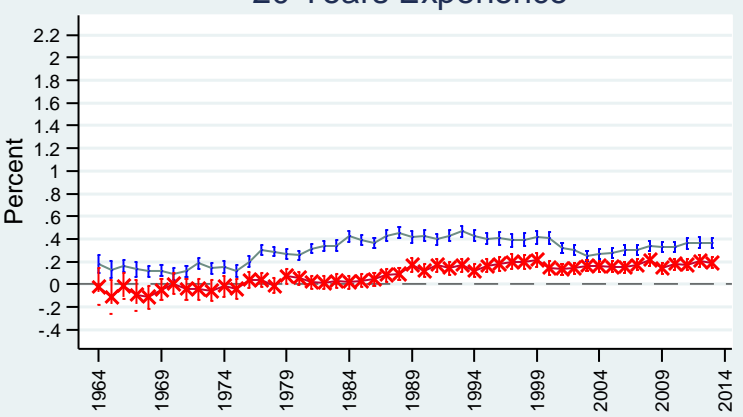

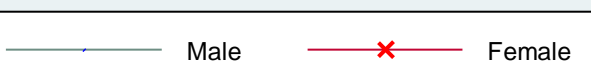

Note: Average Marginal Effect with Confidence Interval 


\section{A.1.3: OLS, education, log real hourly earnings}
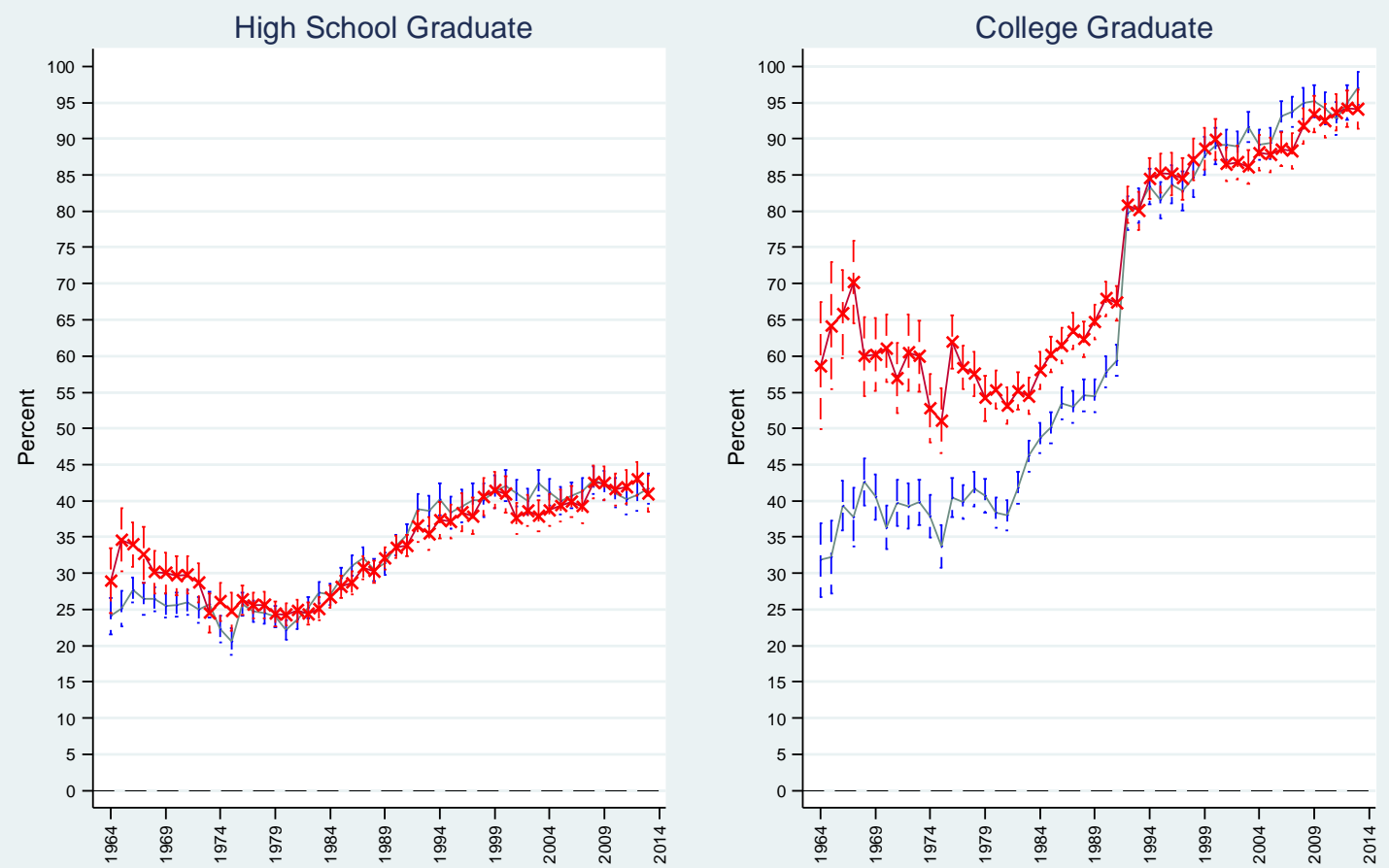

Note: Marginal Effect 